\title{
17
}

\section{THE CONUNDRUM OF ARTICULATING SOCIETAL KNOWLEDGE AND TECHNOLOGY DEMAND}

\section{Cees Leeuwis}

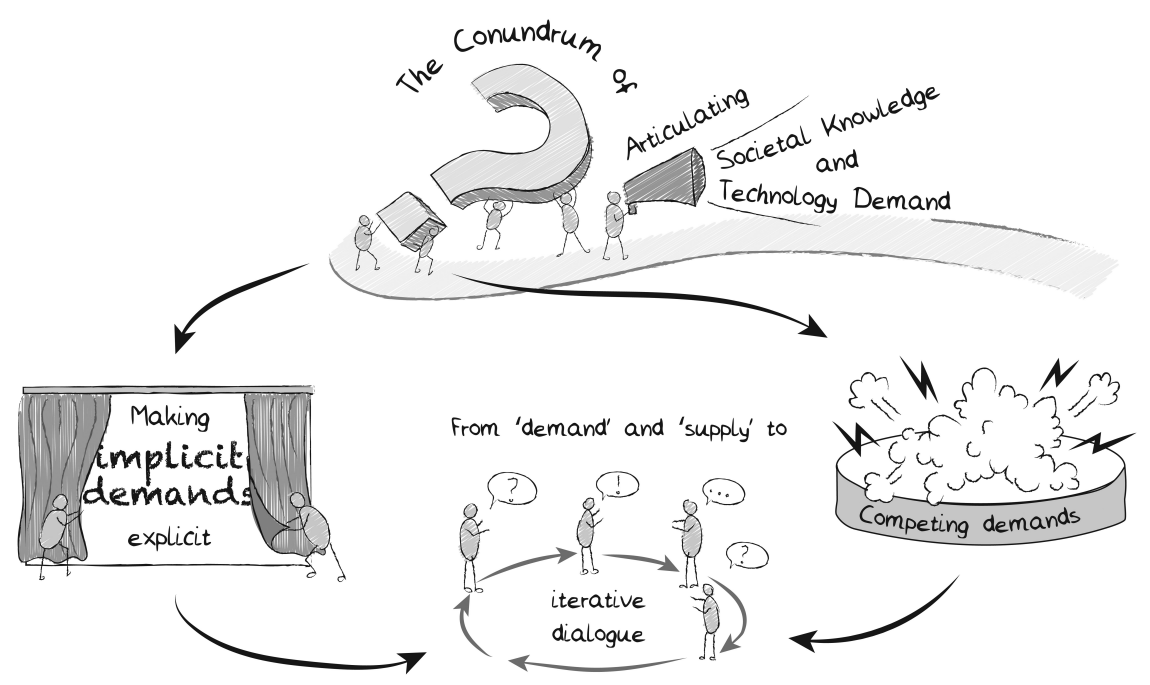

\section{Introduction}

Although there is considerable investment in the production and provision of applied knowledge and technology to beneficiaries in the context of international development efforts, there are many examples where such knowledge is often found less relevant and applicable to prospective users. Both agricultural research and extension organisations, for example, have been sharply criticised for generating and disseminating knowledge and technology that does not match with the needs, demands, and realities of large segments of farming populations (Birner and Byerlee, 2016; Klerkx and Leeuwis, 2008; Laborde et al., 2020). 
In response to this, several authors have called for greater involvement of users in the setting of research and extension agendas. These developments in agricultural research for development resonate with developments in other sectors and contexts, where we see greater attention for democracy and public engagement in the formulation of research agendas (Boon and Edler, 2018). In the Netherlands, for example, this has resulted in a nationwide citizen consultation for the development of the Dutch 'national research agenda' (De Graaf et al., 2017).

Such strategies for 'making knowledge work' are frequently linked to the idea that the articulation of knowledge-demands in society needs to be enhanced. Here, the notion of 'demand' is used primarily in a substantive sense in referring to questions that citizens have, to gaps in understanding that they prioritise, or to criteria that they use in evaluating whether a new technology (e.g. a seed variety) meets their expectations (Almekinders, 2011). The assumption is that the articulation of such demands will serve to make research and extension systems more 'demand-driven' or 'demand-led' (Birner and Anderson, 2007; Kibwika et al., 2009), leading to the production (or co-creation) of more relevant knowledge and technology, and-eventually-to more effective knowledge utilisation and problem solving.

The next section presents several small case-studies that invite reflection on the notions of demand and demand-articulation. With reference to these empirical observations, I critically examine assumptions that underpin the idea of demand-articulation and the expectation that this will enhance the applicability of knowledge generated. In doing so, a better understanding on 'how knowledge works' is created.

In the final part of the paper, I discuss how we can 'make demand articulation work differently.' I propose that we need to embed demand-articulation in collaborative change initiatives, whereby knowledge provision becomes an integral part of efforts to strengthen discourse coalitions for change.

\section{Formative experiences and reflections}

Over a period stretching from the late 1980 s to the present, I was involved in a number of studies that yielded insights into the notions of demand and demandarticulation. Below I summarise some of these experiences and the lessons learned from them.

\section{Case 1: Developing software for horticulturists: discovering demands as a moving target}

A first formative experience dates back to an early stage in the digital revolution, shortly after the introduction of the personal computer in agriculture in the 1980s. However, the story resonates with recent experiences in developing software for mobile Information and Communication Technology for Development (ICT4D). 
In the early 1990s, a group of glasshouse horticulturists in the Netherlands managed to arrange a national subsidy in order to build a software package that would support them in exchanging data and comparing the performance of different glasshouse enterprises. A software company was hired to build the programme, and the process started with several meetings geared towards eliciting a programme of requirements. The growers explicated their interests regarding the functionalities of the software, and had to find a compromise on the data that the package would include. Glasshouse horticulturists specialise in different crops (tomato, cucumber, flowers, etc.) and each crop was associated with specific agronomic and production-related parameters of relevance, while all growers had an interest in analysing production parameters against climatic data. Since the project was supposed to benefit all, it was decided that the emphasis should be on exchanging climatic data since these were the same for all growers. When the programme of requirements was ready, the software developers build the software package.

Once the horticulturists began using the package, they immediately formulated a range of additional ideas, including a wish for graphic presentation of data (e.g. graphs comparing several parameters in selected time periods, cumulative graphs regarding production per week, etc.). However, the subsidy had been spent already, and there were no additional resources available. Meanwhile, a small group of cucumber growers had started a competing initiative because they were unhappy about the compromises made. They engaged a partially disabled arable farmer and computer amateur, developing tailor-made comparison software for cucumber growers in a relatively short time. This amateur continuously engaged with the users and rapidly developed new prototypes based on user feedback, including numerous graphical presentations that were desired by the growers. The costs were a fraction of the subsidised project. The users were very happy with the rapid uptake of their suggestions, but complained about numerous bugs and the continuous stream of updates (Leeuwis and Arkesteijn, 1991).

From this experience we can draw several lessons relevant to demand-articulation.

Demands are diverse. The experience makes clear that demands are diverse even within a group that may seem relatively homogeneous at first sight. In this case, glasshouse horticulturists specialising in different crops wanted the software package to include diverging crop-specific agronomic and production-related parameters. Without such crop-specific information the package had little added value to them. More in general, we know that users and audiences can differ along numerous lines (gender, aspirations, wealth, etc.) that cause them to pose different demands on knowledge and technology, and that a 'one-size-fits-all' solution rarely works.

Demands can be emergent and tacit due to limited experience. The experience demonstrates that the precise needs and demands of users may only become clear after they have been confronted with solutions (see also Bentley et al., 2007). In this case, growers were asked to formulate their demands in advance, but they 
could not articulate sharp and validated demands because it was inherently difficult for them to imagine what the new ICT technologies could do for them. It was only when they were confronted with a working version of the software that they realised and explicated what it was they really wanted. More generally, it is very difficult to formulate a demand in relation to something that one is not familiar with, and one cannot therefore assume that prospective users can always articulate in detail what they want.

The layered character of needs and demands. The experience shows that it is relevant to distinguish between 'needs' and 'demands' at different levels of abstraction. While the growers were able in advance to formulate a broad need at an abstract level ('we want a software package that supports exchange and comparison of on-farm data') they could not yet translate this into more detailed demands (the inclusion of specific parameters and graphic comparison facilities). Thus, demands can be seen as a further translation and operationalisation of a broader need. The formulation of a need (e.g. to have 'a viable farm' or 'a healthy living environment') is much easier than exerting specific and validated demands that will help to realise the broader need and ambition. By implication, processes of demand-articulation need to move beyond 'needs assessment' and find ways of digging deeper into the specific practices and rationales involved.

Participatory projects and methods differ in their capacity to incorporate emergent demands. Experience shows that technologies-in this case software-can be developed in different ways. Arguably, both projects were highly participatory and initiated by growers, but they differed in their approach and level of formality. In order to get access to a government subsidy, the national initiative was required to make use of a professional software company that used a linear development method that made a strict separation between the needs-articulation and the implementation phases. When the software was ready, it was no longer possible to make meaningful adaptations since the project resources were finished. The more localised and amateur-based initiative used an informal 'prototyping' (Vonk, 1990) approach that was very effective for discovering and meeting substantive demands, but at the costs of software technical elegance and sustainability. Thus, we see that formalised project environments can easily impose constraints that hamper the identification and uptake of demands. The challenge then is to fund and organise projects in such a way that emerging demands can be incorporated, i.e., that iteration between actual use and design is possible.

\section{Case 2: Farmer funded research: a process resulting in disappointment}

In 2004, I was approached by representatives of the Dutch Dairy Commodity Board (DCB) with a request to investigate their internal processes of demandarticulation for applied research. The DCB collected farmer levies (a fee per litre of milk produced) and used these to fund applied research on questions generated by farmers, and to translate the findings into extension materials that would 
assumedly be highly relevant to farmers. Despite the fact that farmers generated the initial questions, and even though a farmer committee (the Dairy Farming Committee, DFC) had full control over resources and fund allocation, the DCB had worries about the relevance of the knowledge being generated. Farmers were not appreciative of the research findings that were communicated, and questioned whether they should continue to collectively fund research at all. I was intrigued: how could it be that the relevance of knowledge generated seemed so poor in a situation where the degree of farmer ownership, participation, and control seemed so high?

We investigated the entire process from exploring farmer demands to research implementation and dissemination (Klerkx et al., 2008), and concluded that there were several missed opportunities for enhancing relevance. In a nutshell, possible questions for research were mostly solicited at the end of regional farmer meetings that had a much broader agenda. Questions from different regions were then collated and grouped by a DCB official. Subsequently, questions were passed on to researchers for assessment and advice, whereby most questions tended to be dismissed as being 'too operational and not requiring additional research.' Remaining questions would typically be prioritised by a committee of DFC farmers and DCB officials, after which researchers developed research proposals that were subsequently approved or rejected by the DFC, and then further operationalised and implemented in a research facility (for details, see Klerkx et al., 2008).

Strikingly, the farmers who had initially posed the questions were not included in these subsequent stages and had no opportunity to interact with officials or researchers to discuss the specific context or the 'questions behind the question.' In addition, research tended to be carried out in researcher facilities (and not on-farm) and without any direct involvement of farmers. Overall, it appeared that the process was organised in such a way that researchers had a high degree of influence on the eventual framing of the research questions, the methodologies used, and the conclusions drawn. At no point in the process was there serious interaction between the farmers posing the questions, other stakeholders that might be relevant to the perceived problem setting, and those who were mandated to generate answers. We concluded that an in-depth articulation of demand (and also 'supply') did not occur, and that the subtleties of the process and the institutional setting offered researchers a lot of opportunities to steer research in directions that fitted their rationales and preferences.

From the above example we can learn several things.

Demands are negotiated in an arena with unequal opportunities to exert influence. In this experience we see that the local questions and demands from farmers were filtered and transformed in a process that involved bureaucrats, researchers, and high-level farmer representatives. The assumptions, criteria, and interests of these parties became leading strands, resulting in research projects that largely reflected their needs and demands rather than those of the farmers. This was possible because those formulating questions had no voice in the transformation 
process, while others were empowered to make their expertise, preferences, and interpretations count in developing and implementing research proposals. Thus, the demands that are actually catered for are the outcome of a negotiation process that is affected by the way in which the interaction is organised (see also Bukenya, 2010).

Diverging lifeworlds complicate the formulation of demands for 'research.' In this example, we also see that prospective users were asked to formulate demands in relation to something abstract ('research') that they were not necessarily familiar with. Arguably, understanding what scientific researchers can or cannot do requires fairly intimate understanding of different scientific disciplines, methods, and available knowledge and research approaches. Clearly, most farmers had little awareness of these. It was therefore not surprising that bureaucrats and researchers could dismiss most issues raised as 'not requiring additional research' or 'non-researchable.' Similarly, bureaucrats and researchers tended to have limited contextual understanding of the challenges that emerge in everyday farming practice, and therefore had little to no access to the world from which the issue or question emerged. In essence, we see that users and researchers may live in different taken-for-granted worlds (or 'lifeworlds,' Schutz and Luckmann, 1974) that do not easily become connected and linked in a meaningful manner.

\section{Case 3: Potato diseases in Ethiopia: the importance and limitations of knowledge}

Potato production in Ethiopia (and elsewhere) is severely affected by several diseases, including late blight and bacterial wilt. The micro-organisms that cause the disease can spread through various routes (e.g. wind, water, soil, seed), which means that farmers can easily infect neighbouring farms if they do not burn diseased plants, disinfect tools and boots, prevent water run-off to other fields, buy clean seed (in case of bacterial wilt), and/or spray against the disease (in case of late blight).

A study by Tafesse et al. (2018) indicated that farmers had very limited knowledge about the existence of damaging micro-organisms and the mechanisms through which they spread, and that most farmers therefore did not realise that successful disease management was highly dependent on the behaviour of their neighbours. In response, several learning-oriented interventions were implemented to foster a greater understanding of the dynamics of the disease for farmers (Damtew et al., 2020).

Although these activities were indeed fruitful, having access to knowledge about disease symptoms, spreading mechanisms, and interdependence was far from sufficient, not least because effective application of such knowledge in Ethiopia essentially required the introduction of a community-based disease management system, rather than a system that relied on individual action only. Typically, collective forms of disease management would need to include an agreement about rules and bylaws to be applied, the establishment of committees 
monitoring both disease occurrence and adherence to agreements by community members, the implementation of a sanctioning system for those that violated agreed-upon rules, and the development of an organisational model to support all this (Tafesse et al., 2020).

Demands can be latent due to gaps in understanding. This experience confirms that it can be difficult to develop understandings and demands about phenomena (i.e., spreading mechanisms of bacteria and viruses) that are largely invisible to the eye (Bentley et al., 2007). Farmers could see the disease symptoms and identify a need for solutions, but few farmers could articulate a demand for knowledge about spreading mechanisms or for community-based disease management, even though this would be highly relevant to them from the perspective of scientists. Parallel to the case about ICT development described above (where growers knew about ICT but had limited experience) we see that it is very difficult to articulate demands about something one does not know about already. In such cases, we could say that users may have latent demands; demands that they cannot formulate in detail but that they would be likely to articulate if they had more usable and relevant information. This is of course a tricky area for researchers, as it offers ample opportunities for them to promote knowledge and technology under the pretext that 'users do not understand anyway.' While latent demands can certainly exist, it is important to realise that one still needs to validate and test what they look like in practice.

Fulfilling knowledge demands is not sufficient. The experience also makes clear that having knowledge about something at an individual level is not a sufficient condition for effective action. In this case, knowledge could only be made effective in concert with other farmers; that is, in a relational setting and in conjunction with institutional issues such as agreement, trust, rules, organisational arrangements, and sanctions. There are many examples showing that new knowledge and technology can only be applied when social and institutional environments are reconfigured (Adjeih Nsiah et al., 2008; Kilelu et al., 2014; Sartas et al., 2020) and achieving this requires radically different kinds of processes than simply detecting and addressing gaps in knowledge and understanding (Geels, 2002; Leeuwis and Aarts, 2011). Similarly, even at the individual level, socialpsychological research demonstrates that knowledge is only one of the drivers of human behaviour (Ajzen, 1985). Thus, the focus of researchers and professionals on issues pertaining to research, knowledge exchange, and knowledge demand is a rather artificial insertion into reality, and arguably rather myopic.

\section{Case 4: Privatised extension delivery on environmental issues: $a$ voucher system to stimulate demand}

Animal production systems in the Netherlands are very intensive, and rely on the massive import of animal feed from countries such as Brazil and Thailand. This has resulted in the overuse of animal manure and serious environmental degradation in rural areas. In the 1990 s, the Dutch government took several measures 
to reduce emissions from animal production, including a compulsory bookkeeping system through which farmers had to register incoming and outgoing flows of nutrients such as nitrogen and phosphorus, and to pay fines in case of serious losses. The government also withdrew animal production rights after a major crisis with swine fever.

While the bookkeeping system was seen as highly complicated and bureaucratic, the latter measure was regarded by most farmers as 'theft' and a 'stab in the back.' In short, the relation between public authorities and farmers was far from optimal. In this context, the government started an experiment with a form of privatised extension (Klerkx et al., 2006). The Ministry of Agriculture had noted that farmers were not very active in seeking advice on how to reduce their nutrient use, and it wanted to support farmers in doing so through a sophisticated voucher system. In essence, all farmers in the Netherlands received a voucher of 250 euros, which they could spend at a private service provider to get advice and support on nutrient management. Before spending their voucher, they could participate in facilitated group sessions that would help them to discover their needs, and a website with certified advisory products was supposed to help them choose an appropriate service. The government investment was legitimised with reference to the idea that caring for the environment would not yield immediate economic benefit for farmers. The vouchers were seen an instrument that would persuade farmers to become more active, and to discover how they might also benefit from improved nutrient management.

Our study on how farmers responded to this opportunity revealed several things. First of all, it showed that relatively few farmers were initially interested to spend the voucher even though it was free. Many farmers argued they did not have a nutrient management problem, and that they had sufficient knowledge and understanding already. Moreover, the large majority of those who eventually did spent the voucher (about one third of those eligible) were actually persuaded and pushed into its use by their regular private service providers; they regarded the voucher mainly as a discount from the price of services that they already had to pay for in relation to such things as nutrient bookkeeping (Klerkx et al., 2006).

Confusing political, economic, and substantive demand. This experience demonstrates, again, that demands come about in a negotiation space where different actors have different interests. Politicians and public administrators demanded that extension services provide farmers with content on nutrient management, which incentivised privatised service providers to push farmers in using opportunities for free advice and support services. However, farmers expressed that they were not interested in additional knowledge about nutrient management, indicating that they had no internalised substantive demand. Although such expressions were in part a form of resistance against the government (with whom relations had become seriously strained) it is indeed also questionable whether farmers lacked knowledge on the topic in the first place. If they had wanted to reduce nutrient use, most of them indicated that they knew how. The problem was that they did not aspire to reduce nutrient use in the context of strained 
relationships. The government tried to compensate the lack of substantive demand by creating an artificial demand in the economic sense (a voucher to buy a service). The example makes clear that the notion of 'demand' can have substantive, economic, and political connotations, and that the possibility of exerting an economic demand (buying a service) does not guarantee a substantive demand. Similarly, there are many situations in the world where clients may have a (latent or explicit) substantive demand, but do not have the financial resources or political space to exert that demand (Nederlof et al., 2008; Feder et al., 2011).

\section{Case 5: Conflicting interests in conservation-induced resettlement: the sensitivity of meeting knowledge demand}

In the beginning of this century, the government of Mozambique aimed to resettle communities who were living in Limpopo National Park, because the removal of fences separating neighbouring national parks in Zimbabwe and South Africa would lead to intensified tension between human inhabitants and wildlife. The inhabitants of the Park were far from happy about moving elsewhere and were involved in negotiations with the government about compensation and further conditions for their departure. Neither communities nor Park authorities had precise knowledge and information about the quantity and quality of natural resources (e.g. arable land, grazing land, water, trees, etc.) that people living in the Park were accessing, and how this compared to resources they would be able to use in their projected area of resettlement. A PhD candidate who lived in the first community that was to be resettled started to make an inventory of such natural resources (Milgroom, 2012). She measured fields with a GPS device and gathered additional information through in-depth interviews and focus group discussions. Through her data collection efforts she became a valuable resource of information for both the communities and the Park authorities. The latter learned that they had under-estimated the resources that inhabitants in the Park used, and through the data collection efforts the communities became more aware that they were likely to lose out on resources. As a result, communities started to make stronger demands for compensation and the negotiations between inhabitants and Park authorities heated up considerably. Meanwhile, the researcher was kicked out of the Park as the authorities felt that her presence and data collection activities were delaying the resettlement process as well as becoming a political threat.

Knowledge as a weapon in the struggle. This example indicates that the creation and sharing of knowledge and information can be highly sensitive, especially when it fulfils a demand and strengthens the position of parties in a negotiation process (Giller et al., 2008). Knowledge and information can be used to support arguments for or against certain courses of action, and in some sense can be seen as a 'weapon' that stakeholders can use in their struggle. Thus, meeting demands for knowledge can - at least temporarily-lead to increased tension and conflict (Milgroom, 2012). 
The research process can have societal impact before the results are clear. While knowledge is often regarded as insights that are formulated at the end of a research trajectory, this example shows that the research process also matters considerably. In the case described above, it was the process of data collection (measuring fields, conducting interviews) that awakened the communities' awareness and which led them to become more assertive in their negotiations with the Park. Wellarticulated research findings and conclusions about the quantity and quality of resources were formulated only at a much later stage, long after the negotiations were over. Thus, it was the research process that had societal impact, and not the research findings (Milgroom, 2012). In line with this, the research methods used also had a performative dimension. Had the researcher used satellite images and algorithms to determine the quantity and quality of resources available, then it is very unlikely that there would have been an impact on the negotiation process.

\section{Making demand-articulation work: embedding knowledge provision in the ongoing dynamic}

The above experiences and lessons make clear that demand-articulation is not an easy and straightforward process, and that it is too simplistic to assume that identification of knowledge demands in society seamlessly results in more relevant knowledge production and greater utilisation. We have seen that societal demands for knowledge and technology are interactional; that is, they arise and emerge in a specific context where people engage with others (including allies, adversaries, and knowledge providers) to negotiate and realise specific ambitions. Thus, demands are not neutral and are part and parcel of politically laden views and strategies regarding desired futures. The small case-studies also suggest that the discovery, specification, and verification of demands can benefit greatly from intensive interaction with potential knowledge and technology providers over a period of time. In other words: the articulation of societal demand for knowledge and technology requires a high-quality process of interaction between the 'demand' and 'supply' side (Bentley et al., 2007; Klerkx et al., 2008). Below, I will outline some further thoughts related to what a 'high quality' process may look like and how those who are seen to be at the knowledge providing end may contribute to this.

Engaging with ongoing initiatives for change. Real demands emerge when societal stakeholders want to achieve something and bring about change. Thus, it may be wise for knowledge providers (e.g. research and extension staff) who want to be societally relevant to link up with 'where the action is' and connect to already ongoing initiatives and existing coalitions for change in society, rather than to start 'from scratch.' This simultaneously implies a commitment to the values that are pursued, and a willingness to address value-laden questions while maintaining scientific and/or professional integrity. Preferably, such engagement and commitment last for a prolonged period, as it may take time to discover and address demands. Moreover, relevant demands evolve over time as change 
processes-which tend to be slow-progress. In essence, the suggestion is to place knowledge provision and research 'in development,' rather than to do them from an outsider position 'for development' (Leeuwis et al., 2017).

From 'demand' and 'supply' to iterative dialogue. Notions like 'demand' and 'supply' have linear connotations as they tend to reinforce the misleading idea that there is a clear separation between those at the sending and the receiving end (Leeuwis, 2000). In a process of mutual engagement all parties involved have something to offer and something to ask for, and indeed formulating what the relevant questions are is equally (if not more) important to knowledge production than devising strategies to answering them. Overcoming the significant differences in taken-for-granted life-worlds between societal stakeholders with tacit contextual experience and those with scientific training requires an in-depth and iterative process of exchange and dialogue, whereby observation and listening to what is said and what is treated with silence is of critical importance (Aarts, 2015; Verouden et al., 2016). Thus, careful attention must be paid to how and where such dialogue is facilitated, since it is important to consider that engagement with the everyday bio-physical realities of stakeholders (e.g. agricultural fields, irrigation canals, processing plants, hospitals) can solicit highly relevant conversations (Chambers, 1994).

Maintaining cross-disciplinary conversations along the entire research process. As many societal challenges are multi-faceted, relevant demands are likely to exist vis-àvis several bodies of knowledge. Thus, several disciplines and sources of expertise may need to take part in a dialogue. In cases where new knowledge needs to be created through research activity, it is important to recall that the research process itself can have meaningful impact upon society even before results are ready. Collaborative research with several stakeholders may contribute to changes in relationships, awareness of interdependencies, and the formation of discourse coalitions (Hajer and Laws, 2006) that already contribute to addressing societal challenges. To optimise the impact of the process and create continued opportunities for demand-articulation and knowledge integration (see Ludwig and Boogaard, this volume), it can be important to organise interaction and involvement along multiple stages of research processes, ranging from research design, choice of methods and location, data collection, data analysis, evaluation, and reporting activities (Jalbert and Kinchy, 2016). It is through such joint activities that newly created knowledge enters the societal conversation and can contribute to shifting these as an integral component of achieving societal change (Leeuwis and Aarts, 2011).

Finally, we need to end this discussion of the conundrum of demand-articulation with a caveat. Embedding knowledge provision in a high-quality process along the lines suggested above is easier said than done. It requires considerable skills and capacities on the side of both societal stakeholders and professional knowledge providers (Kibwika et al., 2009). Even more importantly, it requires an institutional environment in research and extension that encourages and incentivises these kinds of engagement and is able to accommodate them organisationally 
and financially. Evidence suggests that dominant ways of financing, staffing, planning, and controlling research and extension activities are often not thus conducive (Leeuwis, 2000; Leeuwis et al., 2017; Sumberg et al., 2017). Changing our own institutional realities is a challenge that we need to address with urgency.

\section{References}

Aarts, M. N. C. (2015). The art of dialogue. Inaugural lecture upon taking up the post of Personal Professor of Communication and Change in Life Science Contexts at Wageningen University on 3 September 2015.

Adjei-Nsiah, S., Leeuwis, C., Giller, K. E. and Kuyper, T. W. (2008). Action research on alternative land tenure arrangements in Wenchi, Ghana: Learning from ambiguous social dynamics and self-organized institutional innovation. Agriculture and Human Values, 25, 389-403.

Ajzen, I. (1985). From intentions to actions: A theory of planned behavior. In: Kuhl, J. and Beckmann, J. (eds.). Action control: From cognition to behavior. Dordrecht: Springer, 11-39.

Almekinders, C. J. M. (2011). The joint development of JM-12.7: A technographic description of the making of a bean variety. NJAS - Wageningen Journal of Life Sciences, 57(34), 207-216.

Chambers, R. (1994). Participatory Rural Appraisal (PRA): Analysis of experience. World Development, 22, 1253-1268.

Bentley, J., Velasco, C., Rodríguez, F., Oros, R., Botello, R., Webb, M., Devaux, A. and Thiele, G. (2007). Unspoken demands for farm technology. International Journal of Agricultural Sustainability, 5(1), 70-84.

Birner, R. and Anderson, J. (2007). How to make agricultural extension demand-driven. The case of India's agricultural extension policy. IFPRI discussion paper 00729. IFPRI.

Birner, R. and Byerlee, D. (2016). Synthesis and lessons learned from 15 CRP evaluations. Independent Evaluation Arrangement (IEA) of CGIAR. http://iea.cgiar.org/

Boon, W. and Edler, J. (2018). Demand, challenges, and innovation. Making sense of new trends in innovation policy. Science and Public Policy, 45, 435-447.

Bukenya, C. (2010). Meeting farmer demand? An assessment of extension reform in Uganda. Unpublished PhD dissertation, Wageningen University.

Damtew, E., Mierlo, Van, B., Lie, R., Struik, P., Leeuwis, C., Lemaga, B. and Smart, C. (2020). Governing a collective bad: Social learning in the management of crop diseases. Systemic Practice and Action Research, 33, 111-134.

De Graaf, B. A., Kan, R. and Molenaar, H. (eds.) (2017). The Dutch National Research Agenda in Perspective. A reflection on research and science policy in practice. Amsterdam: Amsterdam University Press.

Feder, G., Birner, R. and Anderson, J. R. (2011). The private sector's role in agricultural extension systems: Potential and limitations. Journal of Agribusiness in Developing and Emerging Economies, 1(1), 31-54.

Geels, F. W. (2002). Technological transitions as evolutionary reconfiguration processes: A multi-level perspective and a case-study. Research Policy, 31(8-9), 1257-1274.

Giller, K. E., Leeuwis, C., Andersson, J. A., Andriesse, W., Brouwer, A., Frost, P., ... and Windmeijer, P. (2008). Competing claims on natural resources: What role for science? Ecology and Society, 13(2). https://www.ecologyandsociety.org/vol13/iss2/art34/

Hajer, M. A. and Laws, D. (2006). Ordering through discourse. In: Moran, M., Rein and Goodin, R. E. (eds.). The Oxford handbook of public policy. Oxford: Oxford University Press, 249-266. 
Jalbert, K. and Kinchy, A. J. (2016). Sense and influence: Environmental monitoring tools and the power of citizen science. Journal of Environmental Policy and Planning, 18(3), 379-397.

Kibwika, P., Wals, A. E. J. and Nassuna-Musoke, M. G. (2009). Competence challenges of demand-led agricultural research and extension in Uganda. The Journal of Agricultural Education and Extension, 150(1), 5-19.

Kilelu, C. W., Klerkx, L. and Leeuwis, C. (2014). How dynamics of learning are linked to innovation support services: Insights from a smallholder commercialization project in Kenya. The Journal of Agricultural Education and Extension, 20, 213-232.

Klerkx, L., Grip, K. de and Leeuwis, C. (2006). Hands off but strings attached: the contradictions of policy-induced demand-driven agricultural extension. Agriculture and Human Values, 23(2), 189-204.

Klerkx, L. W. A. and Leeuwis, C. (2008). Institutionalizing end-user demand steering in agricultural RandD: Farmer levy funding of RandD in The Netherlands. Research Policy, 37(3), 460-472.

Laborde, D., Porciello, J. and Smaller, C. (2020). Ceres2030: Sustainable solutions to end hunger. Ceres2030. https://ceres2030.org/

Leeuwis, C. and Arkesteyn, M. (1991). Planned technology development and local initiative: Computer supported enterprise-comparisons among Dutch horticulturists. Sociologia Ruralis, 31(2/3), 140-161.

Leeuwis, C. (2000). Learning to be sustainable. Does the Dutch agrarian knowledge market fail? The Journal of Agricultural Education and Extension, 7, 79-92.

Leeuwis, C. and Aarts, N. (2011). Rethinking communication in innovation processes: Creating space for change in complex systems. Journal of Agricultural Education and Extension, 17(1), 21-36.

Leeuwis, C., Schut, M. and Klerkx, L. (2017). Systems research in the CGIAR as an arena of struggle: Competing discourses on the embedding of research in development. In: Sumberg, J., Andersson, J. and Thompson, J. (eds.). Agronomy for development: The politics of knowledge in agricultural research. Milton Park: Routledge, 59-78.

Milgroom, J. (2012). Elephants of democracy. An unfolding process of resettlement in the Limpopo National Park. Unpublished PhD dissertation, Wageningen University.

Nederlof, E. S., Wennink, B. and Heemskerk, W. (2008). Access to agricultural services. Background paper for the IFAD Rural Poverty Report 2011. Amsterdam: Royal Tropical Institute.

Sartas, M., Schut, M., Thiele, G., Proietti, C. and Leeuwis, C. (2020). Scaling Readiness: Science and practice of an approach to enhance impact or research for development. Agricultural Systems, 183.

Schutz, A. and Luckmann, T. (1974). The structures of the life-world. Portsmouth: Heinemann Educational Books.

Sumberg, J. (ed.) (2017). Agronomy for development: The politics of knowledge in agricultural research. Milton Park: Routledge.

Tafesse, S., Damtew, E., Mierlo, B. van; Lie, R., Lemaga, B., Sharma, K., Leeuwis, C. and Struik, P. C. (2018). Farmers' knowledge and practices of potato disease management in Ethiopia. NJAS - Wageningen Journal of Life Sciences, 86-87, 25-38.

Tafesse, S., Lie, R., van Mierlo, B., Struik, P. C., Lemaga, B. and Leeuwis, C. (2020). Analysis of a monitoring system for bacterial wilt management by seed potato cooperatives in Ethiopia: Challenges and future directions. Sustainability, 12(9), 3580-3580.

Verouden, N. W., Van der Sanden, M. C. A. and Aarts, N. (2016). Silence in interdisciplinary research collaboration: Not everything said is relevant, not everything relevant is said. Science as Culture, 25(2), 264-288.

Vonk, R. (1990). Prototyping: The effective use of CASE technology. Hoboken: Prentice-Hall. 


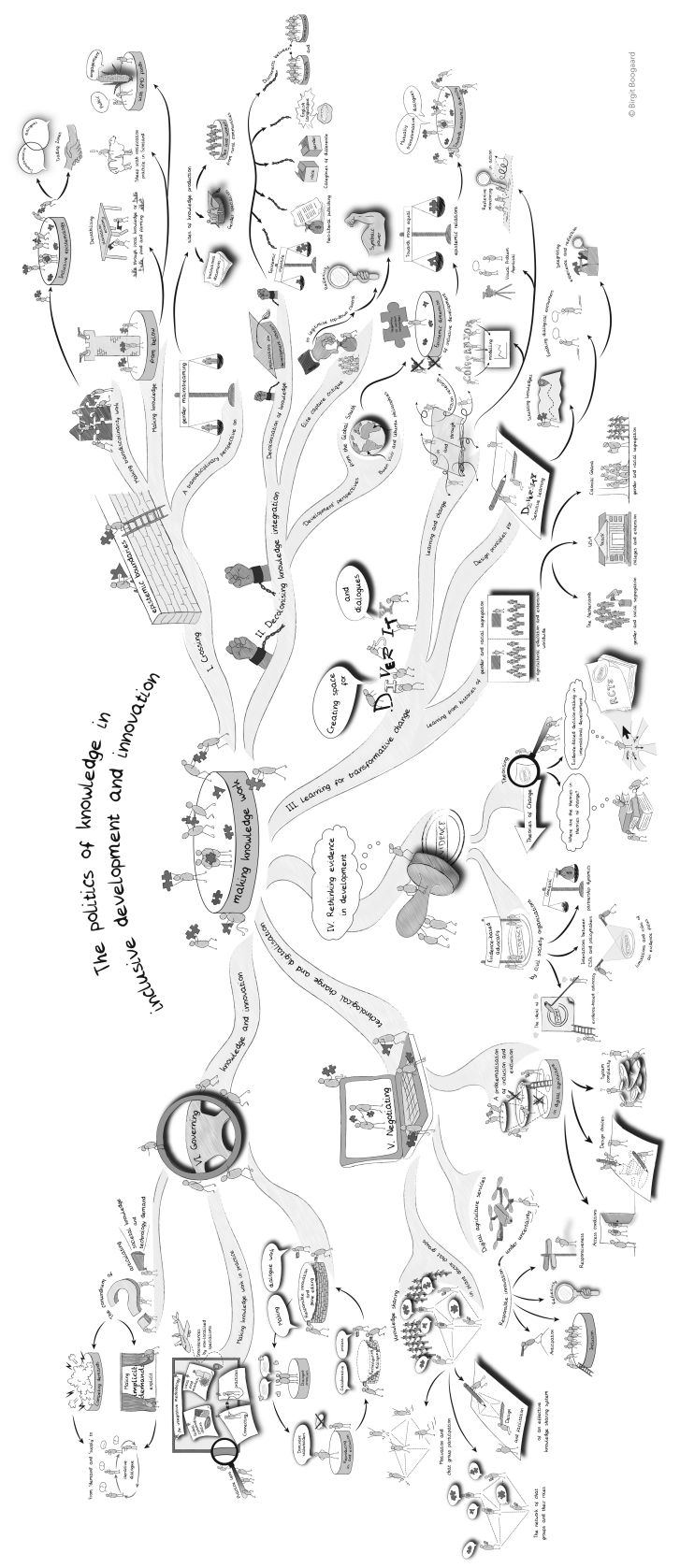

